\title{
Connotation, Significance and Realization Way of "Green"
}

\author{
Jun-Hua LIAO \\ Tourism and Aviation Service College, Guizhou Minzu University \\ Guiyang, Guizhou, China, 550025 \\ E-mail:junhualiao0321@126.com
}

Key words: Green, Connotation, Significance, Realization way.

\begin{abstract}
Green" is a new task of economic development, which is a new requirement for the construction of ecological civilization, which reflects the party and the state to the development of human society more profound understanding. The "green" represents a new outlook on development, values, people's livelihood and wealth; "green" is the construction of ecological civilization and is the inevitable requirement to improve the quality of the national economy and is leading the objective need of the ecological civilization in the world, is a symbol of the new economy normal, which determines the direction and target of "new four modernizations" development. "Green" is for all levels of government adjustment structure, turn the way to guide the new direction, and unswervingly follow the path of "green" road, will usher in the economic transformation and upgrading of China and overall development.
\end{abstract}

\section{Introduction}

In March 2015, the central government introduced the "on accelerating the construction of ecological civilization first opinion" mentioned in the "green" requirements, from the construction of new comprehensive national strength and international competitive advantage to a high degree of understanding and practice of green, reflects the understanding of the party and the state of the development of human society science. Under the new normal, the transformation and upgrading of economic and ecological civilization construction are required to seek the road of green development, green development is the ecological civilization into the political, economic, social and cultural aspects, improve environmental quality and achieve goal of enhancing the well-being of the people. "Green" is the same as the new normal state of economic development in our country, "green" pointed out a new direction for the government to adjust the industrial structure, change the mode of economic growth, "green" is the standard economic new normal direction, goals and evaluation. [1] Therefore, a profound understanding of the connotation, significance and way of realization of "green" is of great significance to the sustained and healthy development of the economy under the new normal.

\section{The Connotation of "Green"}

Green is the original color of nature, but it has a new connotation in the context of ecological civilization. "Green" is the relative environment, while the environment including physical environment (air, water, soil, animal and plant etc.) and the non physical environment (the concept, system and behavior criteria), including the natural environment and social environment. Therefore, "green" includes both the material environment and the natural environment of the "green", but also the non-material environment and social environment of "green"'. The "green" on the one hand, the concept of green development and green values into the green quality; on the other hand, the concept of green development and green values of green production and lifestyle of people and the green consumption mode, outside of the green enterprise development pattern, outside of government green management. [2]

\section{"Green" Symbolizes a New Concept of Development}

Economic development and the protection of the natural ecological environment depend on each other, and they are dialectically unified. A good natural ecological environment is the foundation of 
human sustainable development, and any economic development based on the destruction of the natural ecological environment is short-term and unsustainable. Relying on high input and high energy consumption to promote economic development, relying on low cost and low efficiency to expand the market will lead to depletion of resources and environmental damage, it is difficult to achieve sustained economic and social development. Only when the economic development, and effectively protect the natural ecological environment, in order to achieve efficient and sustainable development. Under the new normal, the central timely put forward the idea of green development, as China's economic transformation and upgrading, development direction, and "green" and new industrialization, urbanization, information technology and agricultural modernization are closely linked, indivisible, central will be "green" and "new four modernizations" are mentioned, rise to the governing level, to adapt to the new situation of China symbol development view.

\section{"Green" Symbolizes New Values}

The natural ecological environment is the material base for human survival and development. Accordingly, the protection and improvement of ecological environment is the prerequisite for the sustainable development of human society. The party's eighteen proposed to vigorously strengthen the construction of ecological civilization, and strive to build a beautiful Chinese, realize the sustainable development of the Chinese nation, has greatly enriched the socialist core value system, to advocate ecological civilization has become the new norm. The essence of "green" is "harmony between man and nature", which is the protection and respect for nature. The development of modern society needs to be based on the protection of the ecological environment, not the destruction of the ecological environment, the high energy consumption and the sacrifice of the green. Only by protecting the natural ecological environment can the development be sustained. Green represents life and vitality, and the development based on green is sustainable. General secretary Xi Jinping has repeatedly stressed that in the process of economic development, we must protect and treat the ecological environment. All these highlight the "green" is a new value.

\section{"Green" Symbolizes a New Concept of People's Livelihood}

With the continuous enhancement of green consciousness, green consumption and green demand gradually become the current trend of the world. [3]After the reform and opening up, after thirty years of rapid development, at present, China's economic aggregate has leapt to the world's second, people's material living standards have been greatly improved. With the gradual affluence of material life and spiritual life, people begin to change from "seeking survival" to "seeking ecology", from "looking for food and clothing" to "looking for environmental protection", and increasing the awareness of ecological environmental protection. Sky blue, green mountains, water is the most basic elements of modern life, at the same time, China is a comprehensive well-off society in the meaning of the title. Once upon a time, the destruction of resources and environmental pollution caused great losses to the state and society, and became a livelihood of the people. In the new normal today, we must adhere to the concept of green development, economic transformation and upgrading can be achieved, and leapfrog development, the people can truly share the reform bonus, and constantly improve its happiness index. Therefore, "green" symbolizes a new concept of people's livelihood.

\section{"Green" Symbolizes a New Concept of Wealth}

It is human nature to give green mountains and rivers of grace, the daughter is difficult to buy, is a great asset. Not only are a steady stream of growth, income, employment, but also wealth; the advantages of environment, resources and ecology are also wealth. Environmental resources turn to development resources, ecological advantages into economic advantages, and the land will promote wealth growth. General secretary Jin-ping Xi brilliantly pointed out that beautiful scenery is the gold and silver mines. In the process of sustained and healthy economic development, both tangible material wealth and intangible ecological wealth are needed. So, in the context of a new normal economy, we need to have a "green" new concept of wealth, the need to release more ecological bonus". 


\section{The Meaning of "Green"}

\section{"Green" is the Sublimation of Ecological Civilization Construction}

In the course of the construction of ecological civilization, China has experienced three major changes in the field of thought: one is for economic development at the expense of the ecological environment; two is to economic development, but also to protect the ecological environment; three is the ecological environment itself is precious wealth. "The rise and fall of ecology determines the rise and decline of civilization," and "the protection and improvement of the ecological environment isthe protection and improvement of productive forces", which is the sublimation of the development concept and mode of development, as well as a revolution in the concept and way of governance. The Seventeenth Party Congress for the first time put forward the construction of ecological civilization, then, from all walks of life has carried on the beneficial exploration to the construction of ecological civilization, made substantial achievements; in 2012, The 18th national congress of the party proposed the construction of "beautiful China", is a further distillation of the construction of ecological civilization; put forward in the third Plenary Session of the 18th CPC Central Committee to take measures of the construction of ecological civilization system is feasible; in the fourth Plenary Session of the 18th CPC Central Committee proposed by the legal system to protect the ecological environment. In March 2015, the central government introduced the "on accelerating the construction of ecological civilization first opinion" mentioned in the "green", marking the China the understanding of the ecological civilization construction and the system also has a new leap, can be said to be a major theoretical innovation of the Communist Party of Chinese, is the sublimation of ecological civilization construction.

\section{"Green" is the Inevitable Requirement to Improve the Quality of National Economy}

After the industrial revolution, along with the process of modernization, the deterioration of the ecological environment has become a major obstacle to the development of human society. How to get out of the ecological predicament has become an important issue in today's society and a core issue of modern civilization in the context of aggravating environmental pollution, deteriorating ecosystems and the increasingly tense relationship between mankind and nature. In the process of modernization in China, such problems as the bottleneck of resources and environment, the deterioration of ecological civilization and the lagging behind of ecological civilization are also faced with the following problems. First, the resource constraints are tight. A lot of resources in our country and the world average per capita is lower than the state, for example, China's cultivated land per capita is only equivalent to the world average of $43 \%$, fresh water per capita is equivalent to the world average of $28 \%$; oil and gas and other strategic resources dependence continues to improve, in 2014 reached 59.5\%, 31\%; development mode is still extensive, China's energy consumption per unit of GDP is 2 times the world average. Second, serious environmental pollution. The problems of pollution of atmosphere, water and soil are prominent all over the country, so it is urgent to strengthen the construction of ecological civilization. Third, ecosystem degradation. Forest coverage is not high, grassland degradation, soil erosion, desertification, rocky desertification and other issues still grim, has not yet fundamentally curb the overall deterioration of the overall trend of ecology. Although China's total GDP has jumped to second of the world, but the quality of the national economy is not high, compared with developed countries there is still a big gap. Therefore, changing the mode of production has become a top priority in our country, and it is inevitable to put forward "green". Therefore, it is the first priority of "green" to change the mode of production (high technology content, low resource consumption, less environmental pollution), and strive to improve the quality of the national economy. [4]

\section{"Green" is an Objective Needed to Lead the World's Ecological Civilization}

The development of green economy has become the trend of the world, in particular, the western developed countries, the implementation of leading green economic development policies and measures in an effort to develop the sustainable development of the global economy entered a new stage of development in the green economy as the main drive. The United States established the 
world's oldest and largest National Park (Yellowstone National Park) in 1872. It was the first country in the world to practice the "green economy". Following the United States, Japan formulated a green development strategy to promote sustained and healthy development of the economy. Germany introduced the green economic research agenda". All these indicate that the world has reached a consensus that the "green" economy is the new engine of world economic growth rather than the shackles of development. In recent years, China has accelerated the pace of the ecological civilization construction, the first report of the Seventeenth Party Congress proposed the construction of ecological civilization in China; the eighteen proposed the construction of "beautiful China", is a further distillation of the construction of ecological civilization; put forward in the third Plenary Session of the 18th CPC Central Committee to take practical and feasible measures for the construction of system of ecological civilization; put forward the fourth Plenary Session of the 18th CPC Central Committee the legal system to protect the ecological environment; in March 2015 the central issued "on accelerating the construction of ecological civilization first opinion" mentioned in the "green", is a sublimation of ecological civilization construction. At present, the Chinese government is trying to build a post-modern ecological civilization, and realize the modernization from the modernization to the Post Modernization era, and build a civilized society. The famous American scholars advocate ecological civilization small John Cobb (first put forward the concept of "green GDP"), Roy Morrison (first put forward the "ecological civilization" concept) as well as a famous scholar John Foster, Philip Clayton, China are very optimistic about the construction of ecological civilization, highly China ecological civilization construction, thought the future is most likely to lead the world ecological civilized country is Chinese. Morrison, an expert on ecology and sustainable development, is even more outspoken: "from 2070 to 2090, China will play a leading role in the world's sustainable development."." China's economic and social sustainable development needs "green", and the global "green" tide needs China's active participation. As a result, "green" is the objective need for China to lead the world's ecological civilization, and to strengthen the "green" exchanges with countries all over the world is one of the important measures for China to shoulder the responsibility of great powers and conform to the world trend.

\section{"Green" Decides the Development Direction and Goal of "New Four Modernizations"}

The party's eighteen major reports put forward the strategic objectives of the new four modernizations, namely, efforts to achieve a new industrialization, information technology, urbanization and agricultural modernization, requiring efforts to promote the coordinated and simultaneous development of the four modernizations. In March 2015, the central government issued the "opinions on accelerating the construction of ecological civilization" for the first time put forward the "green" and put it and the "new four modernizations" in the same important position. "Green" is the inevitable trend of the times, it determines the direction and goal of "new four modernizations" development, and the "new four modernizations" each other, embraced the new industrialization, informatization, urbanization and agricultural modernization needs to "green" direction of development in order to adapt to the new normal, "new four modernizations" must also be green is the new industrialization, informatization, the green urbanization and modernization of agriculture. [1] As to the overall layout of the concept of ecological civilization into the economic, political, cultural and social construction in the whole process of the "five in one", "green" should also be integrated into the whole process of "new four modernizations" construction. Because of the influence factors from the ideology and the level of productivity development, regional differences, in China to promote and implement the "green" in the process, there are still many difficulties, but the governments at all levels should strive to build an ecological civilization, to ensure environmental bottom line. Efforts should be made to develop innovative industries in the eastern developed areas, and the western region should raise its environmental threshold. In a word, "green" and "new four modernizations" blend with each other. The final result of "new four modernizations" is measured by "green", and "greenness" decides the development direction and goal of the new four modernizations. 


\section{"Green" is a Sign of the New Economic Norm}

Our country proposed green development in the "12th Five-Year" plan, the construction of "two type society" (i.e. resource-saving and environment-friendly) strategy, the eighteen Party Congress report clearly further green development is one of the important ways of ecological civilization construction, in March 2015 the central issued "on accelerating the construction of ecological civilization first the views mentioned in the" green "'. At present, China's economy is in a critical period of structural adjustment, transfer mode, the concept of "green" in line with the current economic new normal practice in China, "green" and the new economic norm is closely related to China's economic development will bring infinite opportunity, at the same time, the "green" will promote local the adjustment of economic structure, change the mode of economic growth. "Green" is a revolution in economic development, an innovation of traditional development methods, and a guideline for guiding China's green development. The green concept will mobilize, standardize and encourage all circles of society to change the view of political achievements of leading cadres, promote the green transformation of enterprises, and form a green lifestyle and consumption pattern. Therefore, under the new normal, "green" is an important symbol of China's economic development, but also the inherent requirements of economic transformation and upgrading.

\section{The Way to Realize "Green"}

\section{Establish a Green Development Concept}

Although our country is rich in natural resources, but in the past a long period of time, economic development is a high energy consumption, low efficiency development, at the expense of the environment. Nowadays, China's water, energy and other important resources are in short supply, the ecological environment is facing enormous pressure, seriously affecting the sustainable development of the economy. With the developed countries and regions in the world compared to underdeveloped and low efficiency of the development is the practical difficulties faced by China, based on the national conditions, accelerate economic transformation and upgrading, development is a pressing matter of the moment to achieve a comprehensive well-off society in china. Therefore, the practice of "green" concept of development, the construction of "two types" society, need the whole society to establish the concept of green development, innovation, the whole process will protect the environment and low carbon development into economic and social development, and write a new chapter in the rise of the green China.

\section{Ensure that the Development of Land and Space is Scientific and Rational}

Based on the national main function zoning requirements, follow the "green" concept of development, according to local conditions to develop the regional urbanization and agricultural development strategy, strengthen environmental protection, the implementation of environmental access policy according to the actual situation of different country, to ensure that the focus of development regional layout optimization. To implement the ecological red line system in the economic and social development, the concept of ecological red line runs through all aspects of economic and social development, and all feasible measures are taken to realize the lawful and orderly development of land and space development activities. According to the actual situation of the country, adhere to the partition management and hierarchical control, the establishment of land resources management system of space science, the important ecological areas (such as ecological fragile areas, forbidden Development Zone) set strict control for the red line protection zone, let people share more ecological dividends

\section{Efforts to Build a Green Industrial System}

At present, the development of green industry in China there are policies and laws and the investment environment needs to be improved, the green industry investment imbalance, lack of originality, green industry technology development green industry still exists behind the pollution hazards. Consequently, we should actively integrate into the green development trend of the world, 
speed up the transformation and upgrading of traditional industries, vigorously promote the development of ecological industries, build a green industrial system, and strive to build an upgraded version of our economy. The field of production and life will strive to promote energy diversification and clean production, and actively promote clean energy and renewable energy (for example solar energy, geothermal energy, biogas utilization, etc.) to improve the solar power, natural gas power generation. On the other hand, to realize energy saving, from industrial energy saving to social energy saving (transportation, construction, household appliances, etc.), increase the use of clean energy, and realize low carbon consumption and green development.

\section{Construction of Ecological Towns}

Green development brings opportunities for the construction of ecological towns, and the construction of ecological towns is the inevitable requirement of "greening". All localities should coordinate the development of urban and rural integration, take the green development as the main line, protect the environment of cities and towns, strengthen infrastructure construction, and improve the ecological livability of towns. Urban planning should take full account of the coordination of human settlements and industrial development, strengthen the integration of urban production, and let the residents live and work in peace and contentment. Planning should highlight the local architectural style, the original style and protection of biodiversity in urban, architectural style, do beautiful natural space layout is scientific and reasonable, comfortable living environment, the realization of "mountains and water, nostalgia". City design should pay attention to the traditional culture and the modern new building concept of the combination of ecological construction and highlight urban green, covering the composite use of city space, the use of clean energy, green building, green construction etc.. Efforts have been made to establish ecological civilization demonstration zones at all levels throughout the country, to play a leading role in radiation and to promote the construction of ecological towns.

\section{System Management, Restoration of Ecological Environment}

The treatment and restoration of ecological environment is a very complex and difficult system engineering. Environmental governance depends on the single method and means, so it needs multi medium, multi factor and multi field coordination. No matter is the prevention of haze, sewage treatment and water purification still needs to be coordinated, multi-level and multi field (such as energy, industry, agriculture, transportation, construction, etc.) in order to effectively improve the ecological environment of scientific and systematic science, so as to effectively repair the ecological environment. The restoration of ecological environment system to do the following work: to vigorously promote the prevention and control of water pollution in key river valleys, lakes water to strengthen the protection of the ecological environment, the exploitation and utilization of water resources in the red line strict management and repair; strengthen the management of key ecological system of rivers and lakes, wetlands and mountains, to enhance its ability of sustainable development; the implementation of more vulnerable the area of ecological environment and ecological environment governance system, in order to repair the deterioration of the ecological environment around; carrying capacity should establish early warning mechanism, prevention of environmental capacity.

\section{Foster Ecological Cultural Environment}

Good ecological environment is the realization of "green culture" of the foundation, therefore, the green development process, should deeply excavate the ecological elements in the regional culture, shape the ecological culture brand, construct the distinctive local characteristics and strong flavor of the times of ecological culture system. Is conducive to the cultivation of "green" ecological and cultural environment, on the one hand, we should strengthen the education of ecological environment for the people, enhance their environmental protection consciousness and sense of responsibility; on the other hand, to guide people to practice strict economy and its way of life and consumption patterns change to green, to encourage the purchase of environmentally friendly products, promotion low-carbonand energy-saving products, to resist the high energy consumption 
and high pollution products, to conserve resources and protect the environment into all aspects of people's lives, people choose to promote green consumption mode of low carbon, is conducive to the cultivation of "green" ecological and cultural environment.

\section{Conclusion}

"Green" is a new task of economic development. It is a new requirement for the construction of ecological civilization and reflects the deeper understanding of the development of human society by the party and the state. Green development is an ideological concept, a way of development, as well as a responsibility. The "green" and the current China background of new normal economic development are closely linked, and guide the new direction for the government to adjust the structure to the way, adhere to the "green" direction of development, China's economic transformation and upgrading and leapfrog development will be achieved.

\section{References}

[1] Jian Zhao, Where is the new concept of greenness? China Environment News, , 2015-04-07. (In Chinese)

[2] Guang-jing Cao, "Green" is a new concept of development, People's daily, 2015-05-28. (In Chinese)

[3] Guang-feng Jin, Building green culture and building ecological civilization, Ecological economy, Chapter8, 2000, pp.35-37. (In Chinese)

[4] Bai Lin, Profound understanding of the connotation and characteristics of greening, People's daily, 2015-08-25. (In Chinese) 